\title{
Control of electronic throttle valve using model predictive control
}

\author{
Anshul Khinchi ${ }^{1 *}$ and M.P.R. Prasad ${ }^{2}$ \\ M.Tech Student, National Institute of Technology, Kurukshetra, Haryana ${ }^{1}$ \\ Assistant Professor, National Institute of Technology, Kurukshetra, Haryana ${ }^{2}$
}

(C)2016 ACCENTS

\begin{abstract}
Electronic throttle valve is used in automobile industries very extensively. Its main function is during combustion process to adjust air-fuel ratio by varying the valve plate angle. Generally this valve plate is attached to the accelerator. It implies that control of valve plate is done by driver. Therefore, climatic, road and fuel conditions do not come into consideration. However, this throttle valve consists of much non-smooth nonlinearities like stick-slip friction, backlash and a discontinuous non-linear spring. These nonlinearities make the control of throttle valve very difficult. In this paper model predictive control has been attempted to control the angular position of electronic throttle valve.
\end{abstract}

\section{Keywords}

Electronic throttle valve. Non-smooth nonlinearities, Model predictive control (MPC), Nonlinear svstems.

\section{Introduction}

For maintaining fuel efficiency and emission law, the fuel system in vehicles has been changed a lot in recent years. Electronic Throttle valve plays an important role in automobile engine to maintain air to fuel ratio in desired limits. Generally, these valves are driven by DC motors. These valves improve performance of engine so that vehicle should achieve air quality standards. In automobile engine, throttle valve is mechanically connected to the accelerator, which is controlled by driver. As, valve and accelerator are connected with each other, the flow of air in the engine is determined with respect to accelerator position. So, external or internal conditions do not affect the desired angle of valve plate. The opening of this throttle valve is done by electronic computing module [1-5].

In other words, it can be said that control of throttle valve is a design problem. Its solution is control of the opening of valve plate angle so that appropriate amount of air can enter the combustion engine. The flow rate of air inside the engine controls the output torque and accordingly, speed will be raised or lowered. This throttle valve system consists of much non-smooth nonlinearities which makes the control of the system very difficult. These nonlinearities include stick-slip friction (generally coulomb friction is considered), gear backlash and a nonlinear spring.

*Author for correspondence
Also, parameters of these nonlinearities are very difficult to find out accurately. As a result, uncertainties exist in the system. So, it is assumed that the inherently existing nonlinearities are smooth. In papers [6-10], variable-structure (VS) controllers are proposed for systems with non-smooth nonlinearities. These controllers are paired with sliding mode controller and observer [11]. Hatipoglu and Özgüner [12, 13] also proposed the solution to these kind of nonlinear systems with the help of sliding mode control. This is done on continuous time systems. Again, Özgüner et al. [14] applied discrete time sliding mode control technique on electronic throttle valve systems. Rossi et al. [15] designed a three-level cascaded control structure for throttle body. The first one is an inner current VS controller; second one is an intermediate velocity VS controller, and an outer position digital linear controller. Beghi et al. [16] designed an observer-based Discrete Time Sliding Mode servo controller based on an identified model for a drive-by-wire throttle control system. It has been pointed out in [17] that a VS controller designed for matched uncertain systems may be implemented in an unmatched uncertain system by using a backstepping approach. In this paper, a Model Predictive Controller is designed by approximating nonlinearities of throttle valve system. The structure of the paper is as follows: Section 2 presents the model of the electronic throttle valve, including the friction, the nonlinear spring, and gear backlash model; Section 3 designs the Model Predictive Controller; Section 4 shows simulation 
results; Section 5 highlights the conclusion of the paper.

\section{Dynamic model of electronic throttle valve}

This section introduces the Electronic throttle valve dynamic model as shown in Figure 1. It is a highly non-linear system and consists of a DC motor, nonlinear spring, a motor pinion gear, an intermediate gear, a sector gear and a valve plate. The parameter names and their definitions used in the derivation of the throttle valve's mathematical model are shown in Table 1 [3]. The gear ratio of the intermediate gear to the pinion gear is defined as $\mathrm{K}_{\mathrm{g} 1}=\mathrm{N}_{\mathrm{p}} / \mathrm{N}_{\text {intl }}$, and that of the sector gear to the intermediate gear is defined as $\mathrm{K}_{\mathrm{g} 2}=\mathrm{N}_{\text {ints }} / \mathrm{N}_{\text {sect }}$.

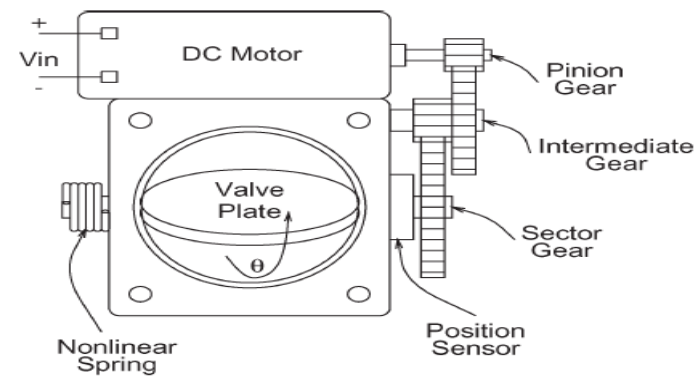

Figure 1 Electronic throttle valve

Table 1 Electronic throttle valve parameters

\begin{tabular}{ll}
\hline Parameters & Definition \\
\hline $\mathrm{J}_{\mathrm{m}}$ & Inertia of Motor \\
$\mathrm{J}_{\text {int }}$ & Inertia of Intermediate Gear \\
$\mathrm{J}_{\text {sect }}$ & Inertia of Sector Gear \\
$\mathrm{J}_{\mathrm{ps}}$ & Inertia of Plate and Shaft \\
$\mathrm{B}_{\mathrm{m}}$ & Viscous Damping Constant of Motor \\
$\mathrm{B}_{\mathrm{int}}$ & Viscous Damping Constant of \\
& Intermediate Gear \\
$\mathrm{B}_{\mathrm{ps}}$ & Viscous Damping Constant of Plate and \\
& Shaft \\
$\mathrm{N}_{\mathrm{p}}$ & Tooth Number of Pinion Gear \\
$\mathrm{N}_{\text {intl }}$ & Tooth Number of Large Intermediate Gear \\
$\mathrm{N}_{\text {ints }}$ & Tooth Number of Small Intermediate Gear \\
$\mathrm{N}_{\mathrm{sect}}$ & Tooth Number of Sector Gear \\
$\mathrm{L}$ & Motor Inductance \\
$\mathrm{R}$ & Motor Resistance \\
$\mathrm{K}_{\mathrm{t}}$ & Motor Torque Constant \\
$\mathrm{K}_{\mathrm{v}}$ & Motor Back emf Constant \\
$\mathrm{p}_{0}$ & Relative Displacement Limit \\
$\mathrm{K}_{\mathrm{r}}$ & Reset Integrator Gain \\
$\theta_{0}$ & Spring Default Position \\
$\theta_{\max }$ & Spring Maximum Position \\
$\theta_{\min }$ & Spring Minimum Position \\
$\mathrm{D}$ & Spring Offset \\
$\mathrm{m}_{1}$ & Spring Gain \\
$\mathrm{m}_{2}$ & Spring Limit Stop Gain \\
\hline &
\end{tabular}

\subsection{Nonlinearities [2]}

2.1.1The nonlinear spring torque, $T_{s p}$ The nonlinear spring in throttle valve is connected to the shaft of throttle. Its function is to reset the throttle plate in case of any failure keeping in mind driver's safety. This spring torque depends upon opening angle of throttle valve [4]. It can be described as:

$T_{s p}=k_{s}\left(\theta-\theta_{0}\right)+D \operatorname{sgn}\left(\theta-\theta_{0}\right)$ where $\mathrm{k}_{\mathrm{s}}$ is the spring coefficient, D is the spring compensation coefficient, $\theta$ is the throttle angle and $\theta_{\mathrm{o}}$ is throttle initial position. Figure 2 represents nonlinear spring.

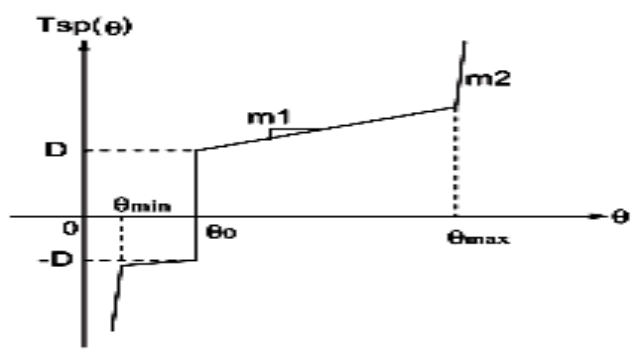

Figure 2 Nonlinear spring

2.1.2The coulomb friction torque $T_{f}$ Various types of friction involved in the motion of throttle plate are viscous, coulomb friction and so on. Here, a simple coulomb friction model is considered which is given by [11]:

$T_{f}(\omega)=F_{s} \operatorname{sgn}(\omega(t))$

where, $F_{\mathrm{s}}$ is the positive constant. Figure 3 shows coulomb friction.

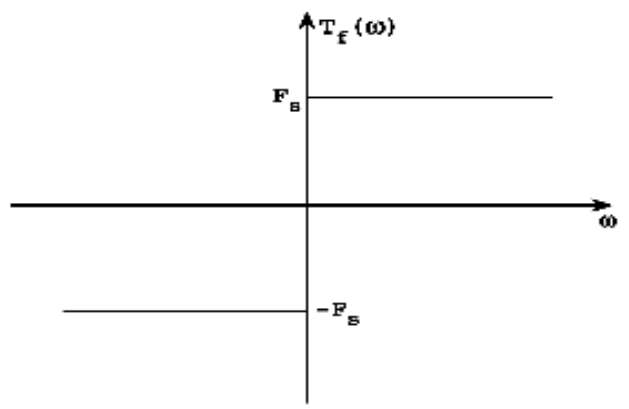

Figure 3 Coulomb friction

\subsubsection{Gear backlash}

There exists backlash nonlinearity between gears, namely pinion, intermediate and sector gear which is expressed as: 
$y=f_{b l}(x, \delta)$

where $\mathrm{x}$ and $\mathrm{y}$ are the input and output torques, respectively, and $\delta$ is the dead band width. The characteristic of the nonlinearity is shown in Figure 4. This nonlinearity is not included in the analysis of the throttle valve model as it is considered as a bounded uncertainty.

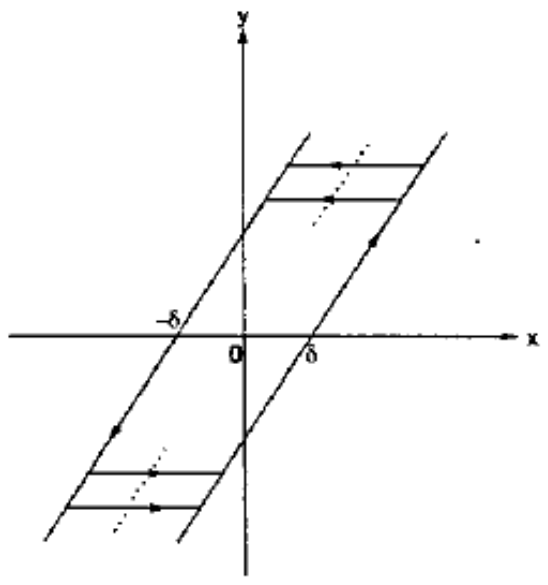

Figure 4 Backlash nonlinearity

2.2Model of throttle valve

Suppose the angular velocity of rotor is defined as $\omega$, and the valve plate position is defined as $\theta$. The total inertia and total damping coefficient are respectively determined by [1], [18]

$J_{t o t}=J_{m}+K_{g 1}^{2} J_{i n t}+\left(K_{g 1} K_{g 2}\right)^{2}\left(J_{p s}+J_{s e c t}\right)$

$B_{\text {tot }}=B_{m}+K_{g 1}^{2} J_{i n t}+\left(K_{g 1} K_{g 2}\right)^{2} B_{p s}$

The dynamic equation taking into account the friction and nonlinear spring torque, is obtained as

$J_{t o t} \dot{\omega}=-B_{\text {tot }} \omega-T_{f}(\omega)-T_{s p}(\theta)+K_{t}$

where $\mathrm{z}$ is the current through the dc motor windings. So, the system can be defined as

$\dot{\theta}=\left(K_{g 1} K_{g 2}\right) \omega$

$\dot{\omega}=-\frac{B_{t o t}}{J_{t o t}} \omega-\frac{1}{J_{t o t}} T_{f}(\omega)-\frac{1}{J_{t o t}} T_{s p}(\theta)+\frac{K_{t}}{J_{t o t}} Z$

$\dot{Z}=-\frac{K_{v}}{L} \omega-\frac{R}{L} Z+\frac{1}{L}$

where $\mathrm{u}$ is the input voltage to the dc motor.
Taking into consideration equations 4,5 and 6 and also by denoting $\theta=\mathrm{x}_{1}$ and $\mathrm{x}_{2}=\left(\mathrm{K}_{\mathrm{g} 1} \mathrm{~K}_{\mathrm{g} 2}\right) \omega$, the dynamic equations of electronic throttle can be written as:

$$
\begin{aligned}
\dot{x_{1}}= & x_{2} \\
\dot{x_{2}}= & a_{21}\left(x_{1}-x_{10}\right)+a_{22} x_{2}+a_{23} z-\mu \operatorname{sgn}\left(x_{2}\right)- \\
& k \operatorname{sgn}\left(x_{1}-x_{10}\right) \\
\dot{z}= & a_{32} x_{2}+a_{33} z+b_{3} u \\
\text { Where, } & \\
\mathrm{a}_{21}= & \mathrm{K}_{\mathrm{g} 1} \mathrm{~K}_{\mathrm{g} 2} \mathrm{~m}_{1} / \mathrm{J}_{\text {tot }} ; \quad \mathrm{a}_{22}=-\mathrm{B}_{\mathrm{tot}} / \mathrm{J}_{\text {tot }} ; \quad \mathrm{a}_{23}=\mathrm{K}_{\mathrm{g} 1} \mathrm{~K}_{\mathrm{g} 2} \mathrm{~K}_{\mathrm{t}} / \mathrm{J}_{\mathrm{tot}} ; \\
\mathrm{a}_{32}= & -\mathrm{K}_{\mathrm{v}} /\left(\mathrm{LK}_{\mathrm{g} 1} \mathrm{~K}_{\mathrm{g} 2}\right) ; \mathrm{a}_{33}=-\mathrm{R} / \mathrm{L} \quad ; \quad \mathrm{b}_{3}=1 / \mathrm{L} \\
\mu= & \mathrm{K}_{\mathrm{g} 1} \mathrm{~K}_{\mathrm{g} 2} \mathrm{~F}_{\mathrm{s}} / \mathrm{J}_{\text {tot }} ; \mathrm{k}=\mathrm{K}_{\mathrm{g} 1} \mathrm{~K}_{\mathrm{g} 2} \mathrm{D} / \mathrm{J}_{\text {tot }}
\end{aligned}
$$

Table 2 shows the nominal values of the parameters in (7) [2]. The approximation of signum function can be taken as:

$\operatorname{sgn}(x)=\frac{2}{\pi} \arctan (x)$

Therefore, the linearized model of the throttle valve model after approximation can be written as following:

$$
\begin{aligned}
& \dot{x}=A x+B u \\
& y=C x+D u
\end{aligned}
$$

Where, $\mathrm{A}$ is the system matrix, $\mathrm{B}$ is the input matrix, $\mathrm{C}$ is the output matrix and D is the feed forward matrix which are given as

$$
\begin{aligned}
& A=\left[\begin{array}{ccc}
0 & 1 & 0 \\
\left(a_{21}-\frac{2 k}{\pi}\right) & \left(a_{22}-\frac{2 k}{\pi}\right) & a_{23} \\
0 & a_{32} & a_{33}
\end{array}\right], B=\left[\begin{array}{c}
0 \\
0 \\
b_{3}
\end{array}\right] \\
& C=\left[\begin{array}{lll}
1 & 0 & 0
\end{array}\right]
\end{aligned}
$$

Table 2 Parameter values for simplifies model

\begin{tabular}{ccc}
\hline S. No & Parameter names & Parameter values \\
\hline 1 & $\mathrm{a}_{12}$ & $1 / 18$ \\
2 & $\mathrm{a}_{21}$ & $-1.6801 \mathrm{e} 3$ \\
3 & $\mathrm{a}_{22}$ & -32.9820 \\
4 & $\mathrm{a}_{23}$ & $4.2941 \mathrm{e} 3$ \\
5 & $\mathrm{a}_{32}$ & -11.6039 \\
6 & $\mathrm{a}_{33}$ & $-5.2087 \mathrm{e} 2$ \\
7 & $\mathrm{~b}_{3}$ & $4.7438 \mathrm{e} 2$ \\
8 & $\mathrm{~K}$ & $4.6139 \mathrm{e} 3$ \\
9 & $\mathrm{M}$ & $2.1073 \mathrm{e} 3$ \\
\hline
\end{tabular}

\section{Model predictive control technique}

This technique was developed around 1970's to meet difficulties faced in oil refineries and chemical plants. But now-a-days, this technique is used very extensively in many industries. It is mainly effective for multivariable system paired with appropriate optimizer. It considers past actions of manipulated 
and disturbance variables on the future horizon of output variables and then it calculate controller moves to get the desired output variables horizon. The output variables are also called as controlled variables (CVs), while input variables are called as manipulated variables (MVs). Measured disturbance variables are called as feed forward variables (DVs) [7].

The other industrial applications of MPC include pulp and paper, cement, power, food processing, automotive, metallurgy, and pharmaceuticals.

There are various advantages of this control technique such as:

- Constraints can be applied on both output as well as input variables. This technique has ability to operate closer to the constraints.
- It can consider inherent non-linearity.

- Time delays, inverse response, changing control objectives and sensor failure are allowed.

- Warnings of potential problems as accurate model prediction are already known.

It is seen in the Figure 5 block diagram that to predict the current values of controlled variables, process model is used. The signal, which is the difference between the predicted and the actual output, acts as a control signal to a prediction block. This control signal is also known as residual. Since, MPC calculations are done at each sampling instant, these predictions are used for: set point calculations and control calculations.

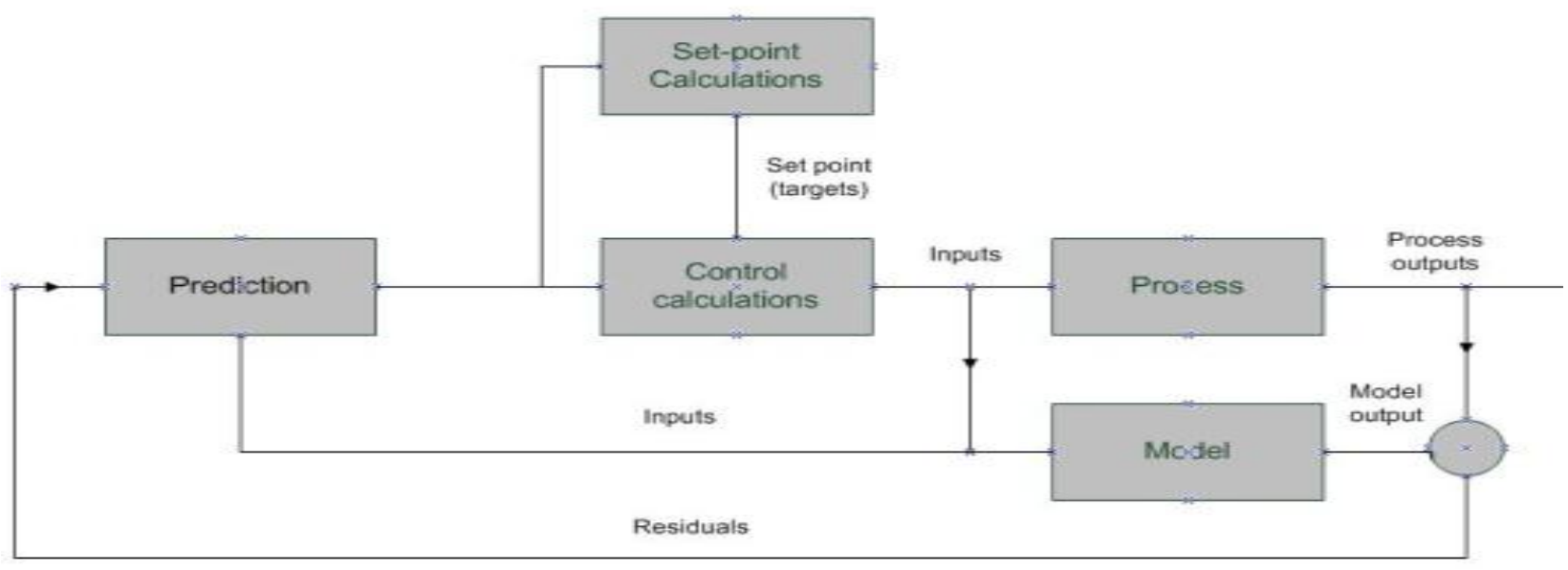

Figure 5 MPC block diagram

The constraints on input and output variables can be applied on both the types of MPC calculations. These model predictive control calculations determine the appropriate sequence of control moves so as to get the optimal results [19]. Figure 6 shows the graphical illustration of MPC technique.

A simple MPC controller used in this configuration has three basic components:

- A process model that predicts the process output in the future up to the prediction horizon (typically, 120 or more scans).

- A future trajectory of the set point for the same number of scans as the trajectory of the predicted process output.

A control algorithm for computing a control action based on the error vector as the difference between the future trajectories of the set point and the predicted process output.

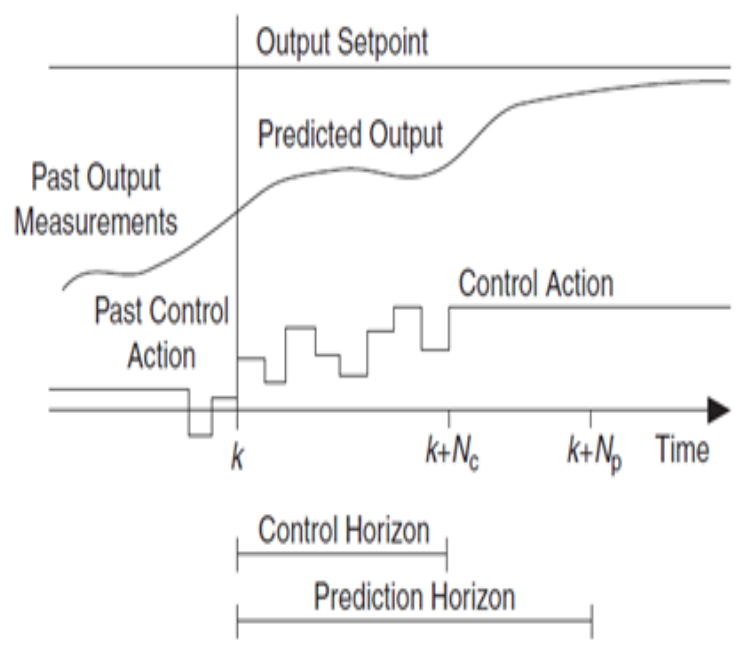

Figure 6 Illustration of the operation of MP 
3.1Process modelling equations of MPC

For mathematical model of controller, predicted controlled variable trajectory of the process is considered as a process state. As a result, modified state space form is used for process modelling. For single-input, single-output (SISO) process prediction, the equations are in the form:

$x_{k}=A x_{k-1}+b \Delta u_{k}+f w_{k}$

$y_{o}=C x_{k}$

where, $\mathrm{x}_{\mathrm{k}-1}=\left[\mathrm{y}_{0}, \mathrm{y}_{1}, \ldots \mathrm{y}_{\mathrm{i}} \ldots \mathrm{y}_{\mathrm{p}-1}\right]^{\mathrm{T}}$ is the vector of controlled variable prediction at a time $\mathrm{k}-1,0,1,2$, $\ldots \mathrm{p}-1$ steps ahead. Matrix A is the shift operator defined for a self-regulating process as:

$\mathrm{Ax}_{\mathrm{k}-1}=\left[\mathrm{y}_{1}, \mathrm{y}_{2}, \ldots \mathrm{y}_{\mathrm{i}} \ldots \mathrm{y}_{\mathrm{p}-1}\right]^{\mathrm{T}}$

$b=\left[b_{0}, b_{1}, \ldots b_{i} \ldots b_{p-1}\right]^{T}$ is the vector of $p$ step response coefficients.

$\Delta \mathrm{u}_{\mathrm{k}}=\mathrm{u}_{\mathrm{k}}-\mathrm{u}_{\mathrm{k}-1}$ is the change in the process input/controller output.

$\mathrm{w}_{\mathrm{k}}=\mathrm{y}^{\mathrm{p}}-\mathrm{y}^{\mathrm{m}}=\mathrm{y}^{\mathrm{p}}-\mathrm{y}^{\mathrm{o}}$ is the process output measurement minus the model output (the mismatch between the process and the model that results from the noise, unmeasured disturbances, and model inaccuracy).

$\mathrm{f}$ is the $\mathrm{p}$ dimension filter vector with unity default values.

Matrix $\mathrm{C}$ is the operator for selecting the current model output defined as

$\mathrm{y}_{\mathrm{o}}=\mathrm{Cx}_{\mathrm{k}+1}$

The MPC controller updates prediction and control calculations every scan. This procedure is known as receding horizon control. For $n$ outputs and $m$ inputs process, vector $\mathrm{x}_{\mathrm{k}}$ has dimension $\mathrm{n} * \mathrm{p}$ and vector $\mathrm{b}$ becomes a matrix $B$ with dimension $n * p$ rows and $m$ columns.

\subsection{Design and tuning parameters of MPC}

\section{$>$ Sampling period $\Delta \mathrm{t}$ and model horizon $\mathbf{N}$ :}

The sampling period given by $\Delta \mathrm{t}$ and model horizon denoted as $\mathrm{N}$ are chosen in such a manner so that $\mathrm{N} \Delta \mathrm{t}=\mathrm{t}_{\mathrm{s}}$. Here, $\mathrm{t}_{\mathrm{s}}$ denote the open loop response settling time.

\section{Control Horizons, $M$ and Prediction Horizons,} P:

The control horizon represented by $\mathrm{M}$, is the set of moves of input variable which are further improved or optimized at the control interval. The control horizon is very less than prediction horizon and lies between 1 and the prediction horizon. The prediction horizon represented as $\mathrm{P}$, is the future control intervals evaluated by prediction as controller optimizes the input variables. Generally, prediction horizon is taken such that $\mathrm{P}=\mathrm{N}+\mathrm{M}$, where $\mathrm{N}$ is the sample time.

\section{$>$ Weighting Matrices, $\mathbf{Q}$ and $\mathbf{R}$ :}

$\mathrm{Q}$ is the output weighting matrix which weights the output variables according to their relative importance i.e. the largest weight will be assigned to the most important controlled variable. This $\mathrm{Q}$ matrix is $\mathrm{mP} \times \mathrm{mP}$ dimensional diagonal matrix. Similarly, $\mathrm{R}$ matrix weights the input variables according to their relative importance. This $\mathrm{R}$ matrix is diagonal in nature and of dimension rM x rM and is also referred to as the input weighting matrix or the move suppression matrix. The diagonal elements, $r_{i i}$ of this matrix are known as move suppression factors.

\section{Simulation results}

This section represents the effect of the proposed control strategy. In this section, we have simulated the dynamic model of Electronic throttle valve system using model predictive control technique considering parameters in Table 2.

Table 3 Designing and tuning parameters

\begin{tabular}{ll}
\hline Designing parameters & Values \\
\hline Control Interval (time units) & 0.2 \\
Prediction Horizon, P & 10 \\
Control Horizon, M & 2 \\
Duration & 10 \\
\hline
\end{tabular}

The design and tuning parameters of the predictive controller taken are shown in tabular form in Table 3. The minimum and maximum constraints on manipulated variables and output variables are taken to be negative infinity and positive infinity respectively [12]. Figure 7 and 9 shows input to the throttle system while Figure 8 and 10 are outputs after applying control technique.

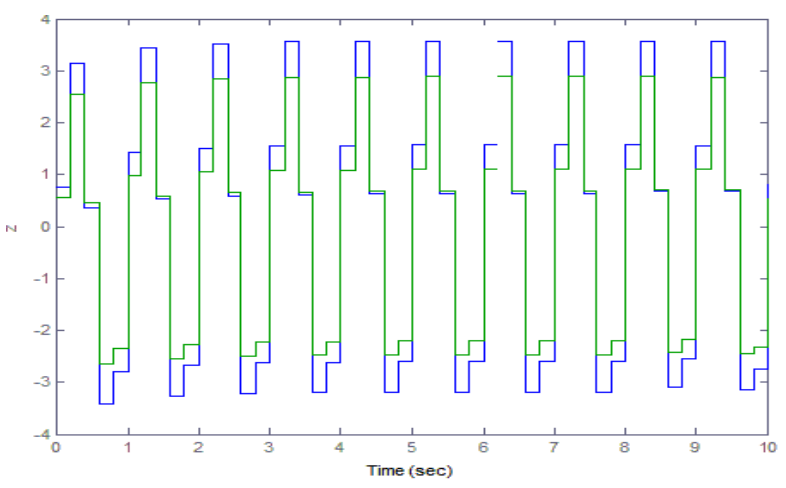

Figure 7 Input to throttle system 


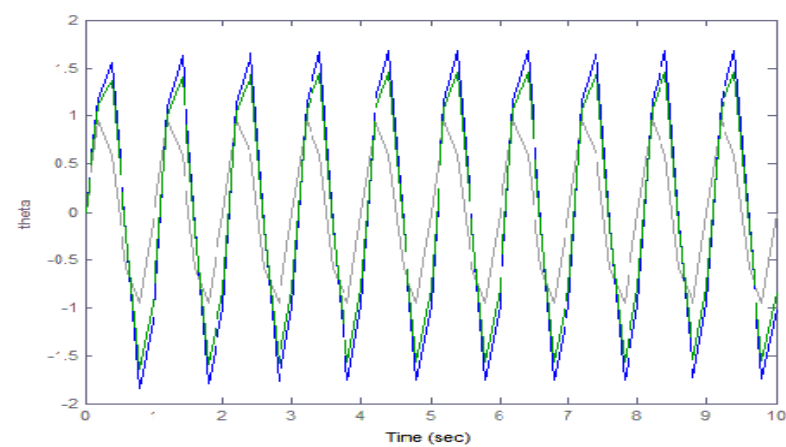

Figure 8 Position tracking for sinusoidal reference signal

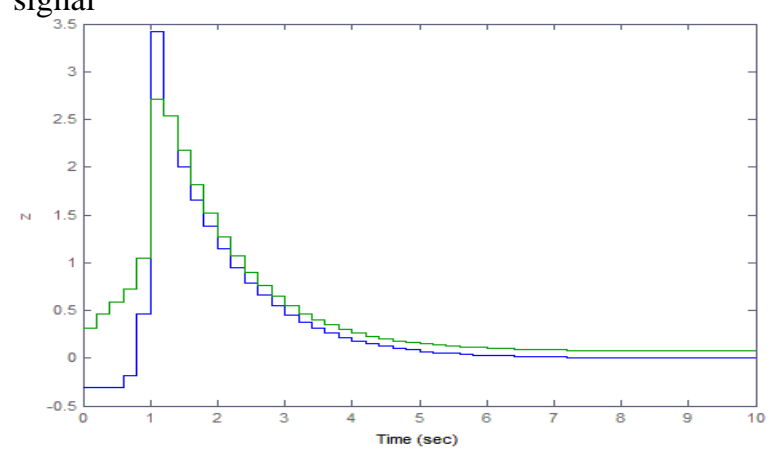

Figure 9 Input to throttle system

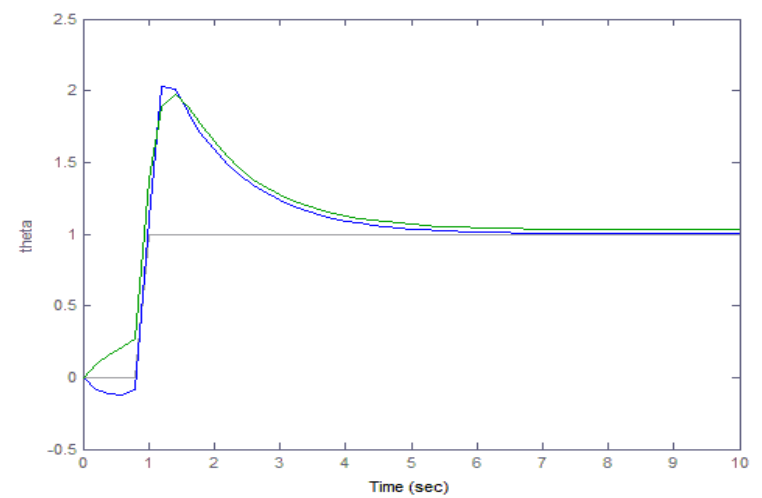

Figure 10 Position tracking for step reference signal

\section{Conclusion and future work}

The dynamic model of electronic throttle valve is developed and certain assumptions have been taken to remodel the valve system. The new control technique, namely Model predictive control is applied onto it. The simulation results shows that the predictive controller of the dynamic model of throttle valve make sure that reference signal is followed by valve plate in presence of non-smooth nonlinearities. In future, the model taken in this work can be controlled with different types of Model Predictive Control like Gain Scheduling MPC or Stochastic MPC or Non-linear MPC, etc.

\section{Acknowledgment}

None.

\section{Conflicts of interest}

The authors have no conflicts of interest to declare.

\section{References}

[1] Aono T, Kowatari T. Throttle-control algorithm for improving engine response based on air-intake model and throttle-response model. IEEE Transactions on Industrial Electronics. 2006; 53(3):915-21.

[2] Kim D, Peng H, Bai S, Maguire JM. Control of integrated powertrain with electronic throttle and automatic transmission. IEEE Transactions on Control Systems Technology. 2007; 15(3):474-82.

[3] Vasak M, Baotic M, Petrovic I, Peric N. Hybrid theory-based time-optimal control of an electronic throttle. IEEE Transactions on Industrial Electronics. 2007; 54(3):1483-94.

[4] Kang S, Yoon M, Sunwoo M. Traction control using a throttle valve based on sliding mode control and load torque estimation. Proceedings of the Institution of Mechanical Engineers, Part D: Journal of Automobile Engineering. 2005; 219(5):645-53.

[5] Naranjo JE, González C, García R, De Pedro T. Cooperative throttle and brake fuzzy control for ACC + Stop \& Go maneuvers. IEEE Transactions on Vehicular Technology. 2007; 56(4):1623-30.

[6] Utkin VI. Methods for constructing discontinuity planes in multidimensional variable structure systems. Automation and Remote Control. 1978; 39:1466-70.

[7] Kaynak O, Denker A. Discrete-time sliding mode control in the presence of system uncertainty. International Journal of Control. 1993; 57(5):1177-89.

[8] Bartolini G, Pisano A, Usai E. Variable structure control of nonlinear sampled data systems by second order sliding modes. In variable structure systems, sliding mode and nonlinear control 1999 (pp. 43-67). Springer London.

[9] Drakunov S, Hanchin GD, Su WC, Özgüner Ü. Nonlinear control of a rodless pneumatic servoactuator, or sliding modes versus coulomb friction. Automatica. 1997; 33(7):1401-8.

[10] Janardhanan S, Bandyopadhyay B. Discrete sliding mode control of systems with unmatched uncertainty using multirate output feedback. IEEE Transactions on Automatic Control. 2006; 51(6):1030-5.

[11] Pan Y, Ozguner U, Dagci OH. Variable-structure control of electronic throttle valve. IEEE Transactions on Industrial Electronics. 2008; 55(11):3899-907.

[12] Hatipoglu C, Ozguner U. Controller design for a class of systems with inherent right hand side discontinuities. In proceedings of IEEE conference on decision and control 1997 (pp. 4024-5). IEEE.

[13] Hatipoglu C, Ozguner U. Handling actuator nonsmooth nonlinearities using variable structure control. In the 14th IFAC triennial world congress (pp. 43-8) Beijing, China 1999.

[14] Ozguner U, Hong S, Pan Y. Discrete-time sliding mode control of electronic throttle valve. In 
Anshul Khinchi et al.

proceedings of the 40th IEEE conference on decision and control 2001 (pp. 1819-24). IEEE.

[15] Rossi C, Tilli A, Tonielli A. Robust control of a throttle body for drive by wire operation of automotive engines. IEEE Transactions on Control Systems Technology. 2000; 8(6):993-1002.

[16] Haskara I. On sliding mode observers via equivalent control approach. International Journal of Control. 1998; 71(6):1051-67.

[17] Kwatny HG, Teolis C, Mattice M. Variable structure control of systems with nonlinear friction. IEEE conferences on decision and control, phoenix, Arizona 1999 (pp. 5164-9).

[18] Hatipoglu C, Ozguner U. Robust control of systems involving non-smooth nonlinearities using modified sliding manifolds. In proceedings of the American control conference 1998 (pp. 2133-7). IEEE.

[19] Qin SJ, Badgwell TA. A survey of industrial model predictive control technology. Control Engineering Practice. 2003; 11(7):733-64.

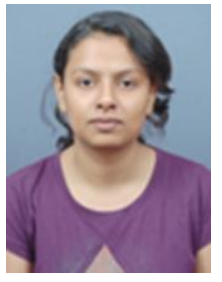

Anshul Khinchi was born in Kota, India, in 1991 on 24th of January. She received the B.Tech. degree in Electronics and Communication Engineering from the Indian Institute of Technology, Design (IIIT) Jabalpur, India, in 2014, and currently pusuing the M.Tech. degree in Electrical Engineering from the National Institute of Technology (NIT) Kurukshetra, Kurukshetra, India. Her interest lies in System Identification and Model Predictive Control.

Email: 24.anshul.khinchi@gmail.com

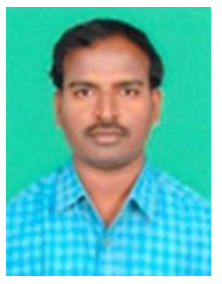

M.P.R. Prasad is pursuing Ph.D from National Institute of Technolgy, Kurukshetra, India. $\mathrm{He}$ is currently working as an Assistant Professor in the Department of Electrical Engineering at NIT, Kurukshetra. He is a member of Institute of Electrical and Electronic Engineers (IEEE). His research interest are Industrial Control, Marine Control and System Identification. 